\title{
Reactive Oxygen Species on Platinum Gauzes during Partial Oxidation of Methane into Synthesis Gas
}

\author{
M. Fathi, ${ }^{*}$ F. Monnet $\nmid \dagger$ Y. Schuurman, $\dagger^{\dagger 1}$ A. Holmen, ${ }^{*}$ and C. Mirodatos $\dagger$ \\ *Department of Chemical Engineering, Norwegian University of Science and Technology, N-7491 Trondheim, Norway; \\ and $\dagger$ Institut de Recherches sur la Catalyse, CNRS, F-69626 Villeurbanne-Cedex, France
}

Platinum gauzes have been studied for the partial oxidation of methane in a high-temperature TAP-2 reactor between 800 and $1100 \mathrm{C}$. Two different oxidation procedures were used and the oxygen uptake has been measured. Alternating pulse experiments with oxygen and methane with various pulse intervals have revealed mechanistic information about the platinum catalyzed partial oxidation. It has been shown that carbon monoxide and hydrogen can be produced directly from methane and solid oxidized platinum. In the absence of gas phase oxygen, the maximum selectivities to carbon monoxide and hydrogen were 97 and $96 \%$, respectively, at a methane conversion of $25 \%$. At low surface oxygen concentrations, oxygen that is incorporated in the platinum bulk diffuses back to the surface to react with surface carbon to carbon monoxide. In that case the surface lifetimes of carbon monoxide and hydrogen are much shorter than the oxygen diffusion time and no consecutive oxidation reactions occur. The results of this study show that production of synthesis gas with high yields is possible by a direct route.

Key Words: partial oxidation; methane; synthesis gas; TAP; platinum; gauzes; bulk oxygen.

\section{INTRODUCTION}

Partial oxidation of methane is an attractive way of producing synthesis gas (1-3). The partial oxidation of methane to synthesis gas can proceed through two routes: (i) indirectly, by total combustion into water and carbon dioxide and subsequent reforming of methane, and (ii) directly, by partial oxidation into hydrogen and carbon monoxide without going through reforming reactions. It has been shown that, under certain conditions and over certain catalysts, carbon monoxide and hydrogen are indeed primary products of the methane oxidation (4-10). This strongly depends on the availability of oxygen and oxygen-surface bond strengths (9). The problem with the industrial imple-

\footnotetext{
${ }^{1}$ To whom correspondence should be addressed at Institut de Recherches sur la Catalyse, CNRS, 2 Avenue Albert Einstein, F-69626 Villeurbanne-Cedex, France. Fax: 33-472445399. E-mail: schuurma@ catalyse.univ-lyon 1.fr.
}

mentation of synthesis gas production through this route is that the primary products are more reactive for further oxidation to water and carbon dioxide with active oxygen surface species than the reactant methane (10). This limits the possible yields of synthesis gas production with methane and oxygen both present in the gas phase without going through reforming. Therefore, recent research on the direct partial oxidation has been directed toward reactions between methane and solid oxygen carriers such as for example $\mathrm{CeO}_{2}$ (11). The idea is that oxygen supplied from a solid phase is less reactive than oxygen supplied from the gas phase.

In order to address the key question about the nature of selective and nonselective oxygen species, a study of the partial oxidation of methane over platinum gauzes was carried out in a new high-temperature TAP-2 reactor. A few studies report on TAP experiments for the partial oxidation of methane $(4,5,9,12-15)$. In most of them rhodium-based catalysts were used. Only two studies report on platinum catalysts (4, 14). Mallens et al. (4) distinguished three different types of oxygen, each being involved in a specific step in the reaction network. Soick et al. (14) carried out a kinetic analysis of the adsorption of methane, carbon monoxide and carbon dioxide over a $\mathrm{Pt} / \mathrm{MgO}$ catalyst. No further information on the reaction mechanism has been reported. In the present study platinum gauzes are used which provide a unique catalyst because of the extremely short length of the catalytic zone. Moreover, due to the low dispersion of these gauzes the number of platinum surface atoms is equal to or lower than the number of methane molecules per pulse. This avoids gradients in the concentrations of adsorbed species along the catalyst layer which is usually the case in TAP experiments and which can complicate the interpretation of the data. The objective of this study is to clarify the reaction mechanism of the partial oxidation of methane at short contact times over platinum and at high temperatures $\left(800-1100^{\circ} \mathrm{C}\right)$. The current study focuses on the different forms of oxygen species and their specific role in the mechanism. 


\section{EXPERIMENTAL}

Woven platinum gauzes (supplied by K. A. Rasmussen, Norway) were used as catalysts. The wires have a diameter of $90 \mu \mathrm{m}$, giving gauzes of $256 \mathrm{meshes} / \mathrm{cm}^{2}$. One single gauze $(70-80 \mathrm{mg})$ is put in the reactor. The TAP-2 reactor is described elsewhere (16). For these experiments a new high temperature reactor was constructed that allows catalyst temperatures above $1000^{\circ} \mathrm{C}$. The high temperature reactor is a 9.0-cm-high quartz cylinder with an inner diameter of $14 \mathrm{~mm}$. The quartz tube is held between two stainless steel flanges. Two water-cooled viton $\mathrm{O}$-rings are used as seals. A large temperature gradient exists along the reactor axis. However, a zone of about $1 \mathrm{~cm}$ is uniform in temperature. The reactor is filled with quartz particles $(0.2-0.3 \mathrm{~mm})$ in which the gauze is placed about $4.0 \mathrm{~cm}$ above the reactor exit. A thermocouple is placed very close to the gauze inside the reactor.

The total number of $\mathrm{Pt}$ atoms in the reactor amounts to $0.5 \mathrm{mmol}$. The number of surface $\mathrm{Pt}$ atoms in the reactor has been estimated to be $10 \mathrm{nmol}$ using data from (17) corrected for the different gauze diameters. The number of methane or oxygen molecules admitted per pulse ( $\sim 20-60 \mathrm{nmol})$ is higher than the number of active sites in the reactor $(10 \mathrm{nmol})$. This implies that the reactant pulses largely influence the surface coverage. The alternating pulse experiments were conducted in the following way: oxygen was injected at $t=0 \mathrm{~s}$, and then methane was injected at a later time, referred to as the pulse interval (between 0.05 and $3.0 \mathrm{~s}$ ). The oxygen/methane ratio was approximately 1 . The pulse size was always verified to be small enough to ensure Knudsen diffusion. The catalyst was prereduced in flowing hydrogen for $30 \mathrm{~min}$ at $900^{\circ} \mathrm{C}$.

\section{RESULTS}

A first experiment was carried out by pulsing methane and oxygen simultaneously over a reduced catalyst at $1000^{\circ} \mathrm{C}$. In Fig. 1 the conversions and yields are shown for the reactants and products as a function of the pulse number. All the oxygen is consumed on the first pulse followed by an almost linear decrease in the oxygen conversion until it levels out around 90 pulses. During the first 70 pulses the methane conversion is rather low $(\sim 10 \%)$ and hardly any products are observed. During this time the baseline at mass 2 increased slowly, indicating the cracking of methane with a slow formation of hydrogen. At the time the oxygen conversion reaches a minimum (90-110 pulses) the conversion of methane increases rapidly and the production of all products is observed. At this point the oxygen conversion increases slightly and the signals of all reactants and products remain stable over a long period of time. In all other experiments the catalyst was always preoxidized.

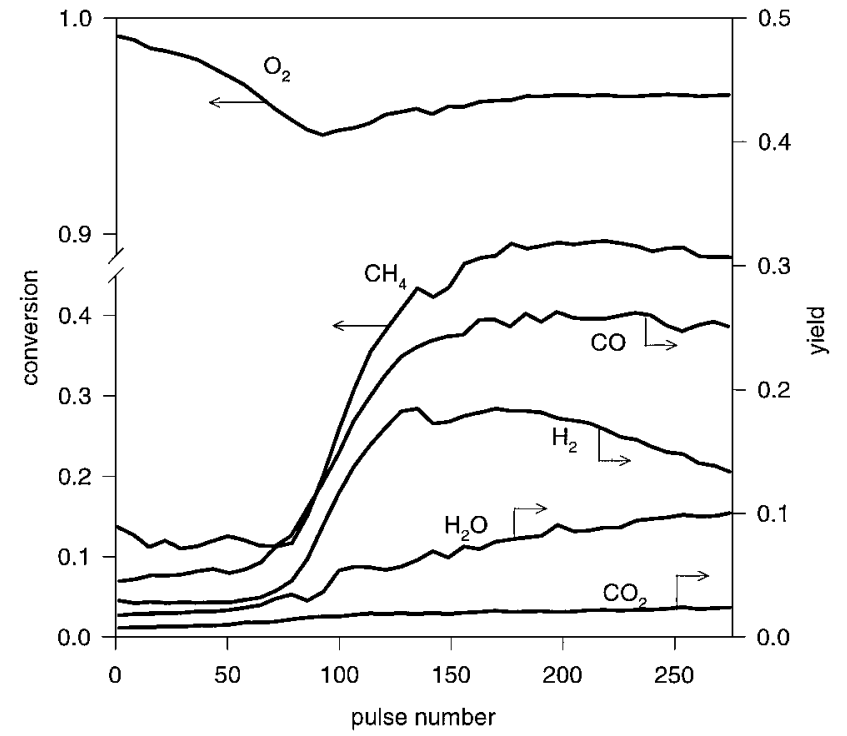

FIG. 1. Conversions and selectivities during simultaneous pulsing of $\mathrm{CH}_{4}$ and $\mathrm{O}_{2}$ over a prereduced $\mathrm{Pt}$ gauze at $1000^{\circ} \mathrm{C}$.

Two methods of oxidation were used and the uptake was measured in both cases:

- By a steady flow of oxygen at 1 bar and at $900^{\circ} \mathrm{C}$.

- By pulsing oxygen on the prereduced catalyst while keeping the reactor under vacuum at $900^{\circ} \mathrm{C}$. Oxygen was pulsed over the catalyst until the oxygen signal was stable.

Under vacuum conditions surface oxygen readily desorbs from the platinum. This was observed by a small additional uptake of oxygen (typical 20-50\% of a single pulse) after a few minutes under vacuum. The oxygen uptakes in the two cases are compared in Table 1 . The amount of oxygen uptake differs significantly for the two pretreatments, but is in both cases far beyond the amount that corresponds to an adsorbed monolayer (assuming a Pt: $\mathrm{O}=1: 1$ stoichiometry). The two different oxidation procedures did not result in any difference in catalyst performance for the oxidation of methane.

The partial oxidation of methane was further studied by using alternating pulses of oxygen and methane over preoxidized platinum at $900^{\circ} \mathrm{C}$ at vacuum conditions. The only varied parameter was the time between the oxygen and the methane pulses $(0.05-2.5 \mathrm{~s})$. Figure 2 shows the calibrated

\section{TABLE 1}

\section{Oxygen Uptake for the Different Applied Procedures on a Prereduced Pt Gauze at $900^{\circ} \mathrm{C}$}

\begin{tabular}{lcc}
\hline & Steady flow of $\mathrm{O}_{2}$ & Pulses of $\mathrm{O}_{2}$ \\
\hline $\mathrm{O}$ uptake & $1.3 \times 10^{20}$ (molec. $)$ & $1 \times 10^{18}($ molec. $)$ \\
$\mathrm{O} / \mathrm{Pt}_{\text {total }}$ & 0.43 & 0.003 \\
$\mathrm{O} / \mathrm{Pt}_{\text {surface }}$ & 26000 & 200 \\
\hline
\end{tabular}




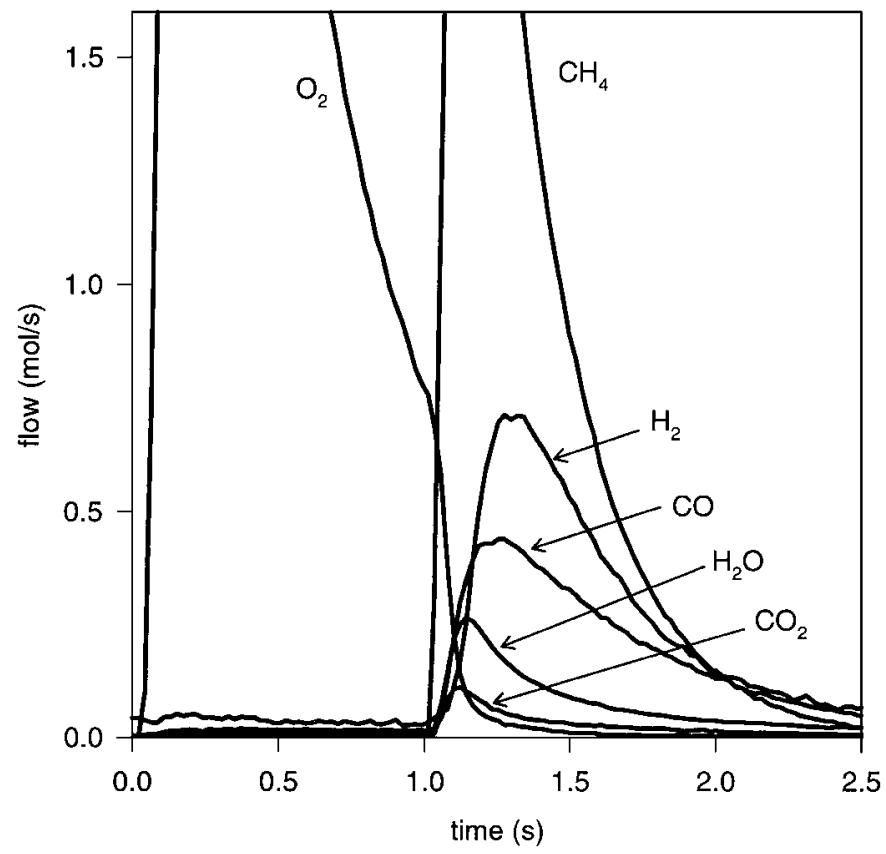

FIG. 2. Transient responses of reactants and products during an alternating $\mathrm{O}_{2}-\mathrm{CH}_{4}$ pulse experiment over a preoxidized $\mathrm{Pt}$ gauze at $900^{\circ} \mathrm{C}$ with a pulse spacing of $1.0 \mathrm{~s}$.

reactant and product responses after an oxygen pulse at $t=0 \mathrm{~s}$ and a methane pulse at $t=1.0 \mathrm{~s}$. This figure clearly shows that when methane is injected, the oxygen signal rapidly drops down to zero. The carbon monoxide, carbon dioxide and water signals appear immediately. When the oxygen signal has almost disappeared, the carbon dioxide and water signals start to decrease. The carbon monoxide signal continues to increase, and finally the hydrogen signal appears. The hydrogen production is clearly delayed until the oxygen signal is almost zero. The carbon monoxide and hydrogen signals reach their maxima at about the same time, long after the carbon dioxide and water. At this time the methane signal is also rapidly decreasing. The decay of the carbon monoxide curve is rather slow and it tails for more than $2 \mathrm{~s}$.

Figure 3 shows the conversion of methane and the selectivities to hydrogen and carbon monoxide as a function of the pulse interval. The methane conversion decreases from approximately 35 to $25 \%$, but the hydrogen and carbon monoxide selectivities are strongly increasing with increasing pulse interval from 25 and $12 \%$ to 96 and $97 \%$, respectively. At a pulse interval of about $2 \mathrm{~s}$, the conversion and selectivity reach steady values.

Experiments using alternating pulses of oxygen and carbon monoxide over a preoxidized catalyst showed very low activity for the oxidation of carbon monoxide at pulse interval of $2 \mathrm{~s}$. The carbon monoxide conversion was about $7 \%$. A similar experiment with oxygen and hydrogen showed a hydrogen conversion of $2 \%$.
To assess the extent of the reaction between carbon dioxide and methane, another similar alternating pulse experiment was carried out by pulsing oxygen followed $2 \mathrm{~s}$ later by a pulse of a mixture of methane $(95 \%)+$ carbon dioxide $(5 \%)$. No conversion of carbon dioxide was observed and the methane conversion was unaffected by the presence of carbon dioxide.

Alternating pulse experiments similar to those in Fig. 2 were carried out with ${ }^{18} \mathrm{O}_{2}$ to further investigate the reactivity of the different oxygen species. The platinum gauze was preoxidized with pulses of ${ }^{16} \mathrm{O}_{2}$. For the alternating pulse experiments ${ }^{18} \mathrm{O}_{2}$ was used on the first pulse. Scrambling into ${ }^{16} \mathrm{O}^{18} \mathrm{O}$ ( 15 to $25 \%$ ) was observed in all experiments. No significant amounts ${ }^{16} \mathrm{O}_{2}$ were observed in these experiments.

Two different pulse responses of $\mathrm{C}^{16} \mathrm{O}$ and $\mathrm{C}^{18} \mathrm{O}$ with two distinct time scales were observed for all pulse intervals as shown in Fig. 4 (curves 1 and 4, respectively). The response of $\mathrm{C}^{16} \mathrm{O}$ is significantly slower than the response of $\mathrm{C}^{18} \mathrm{O}$ and shows a large tailing. The selectivities of $\mathrm{C}^{16} \mathrm{O}$ and $\mathrm{C}^{18} \mathrm{O}$ as a function of the pulse interval are shown in Table 2. There is a clear increase toward $\mathrm{C}^{16} \mathrm{O}$ with increasing pulse interval which slowly levels off at intervals larger than $1 \mathrm{~s}$. Concerning the carbon dioxide formation, $\mathrm{C}^{18} \mathrm{O}_{2}$ is formed first, followed a little later by $\mathrm{C}^{16} \mathrm{O}^{18} \mathrm{O}$ and at last a slow formation of $\mathrm{C}^{16} \mathrm{O}_{2}$ is observed. The relative amounts of the $\mathrm{C}^{18} \mathrm{O}^{18} \mathrm{O}, \mathrm{C}^{16} \mathrm{O}^{18} \mathrm{O}$, and $\mathrm{C}^{16} \mathrm{O}_{2}$ were found to be $2: 2: 1$.

The rate of adsorption of carbon monoxide was investigated by pulsing carbon monoxide over a reduced catalyst.

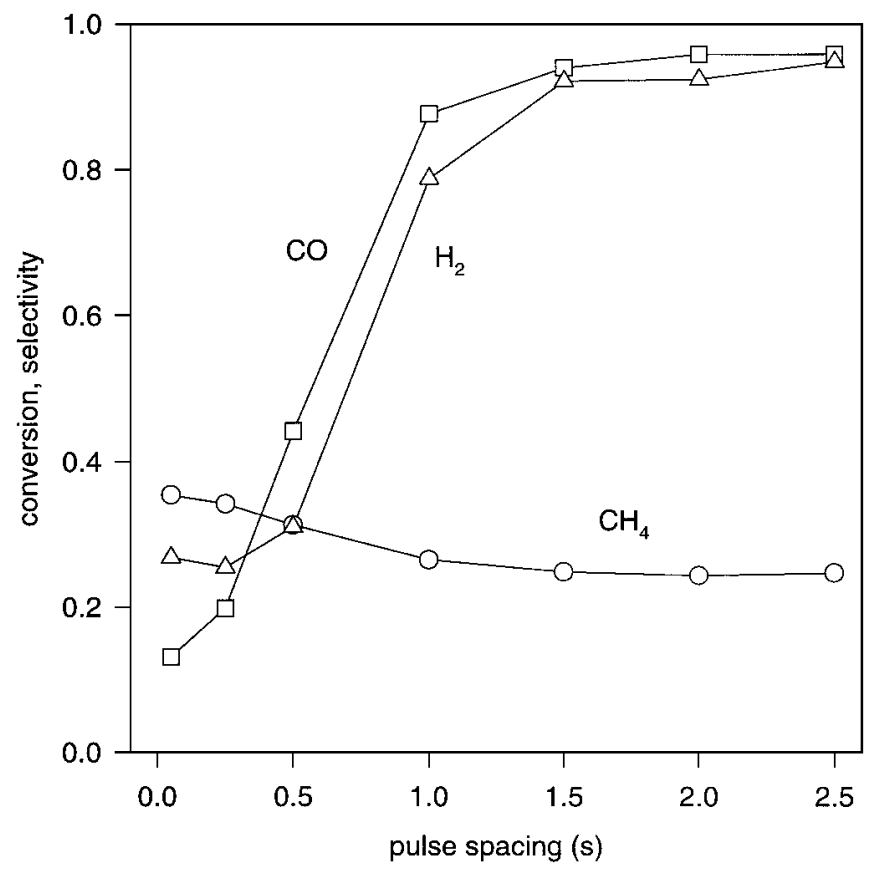

FIG. 3. Conversion of methane and selectivity to synthesis gas as a function of the pulse spacing between $\mathrm{O}_{2}$ and $\mathrm{CH}_{4}$ over a preoxidized $\mathrm{Pt}$ gauze at $900^{\circ} \mathrm{C}$. 


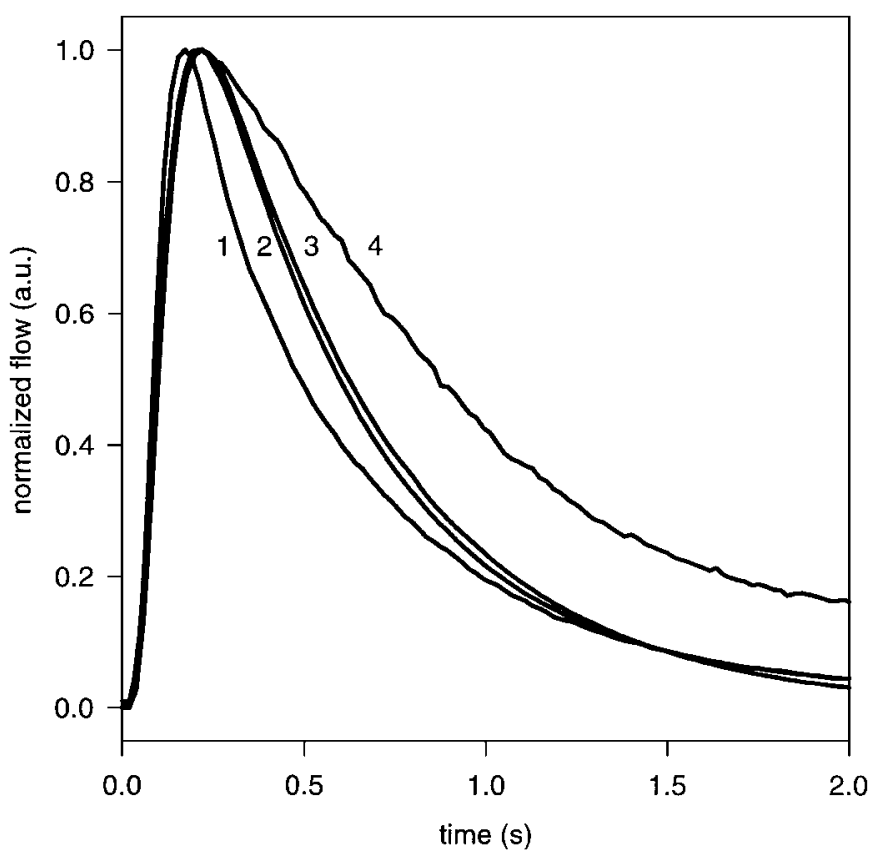

FIG. 4. Height normalized carbon monoxide and argon signals at $900{ }^{\circ} \mathrm{C}$. (1) The $\mathrm{C}^{18} \mathrm{O}$ transient response from alternating pulses of ${ }^{18} \mathrm{O}_{2}$ followed by $\mathrm{CH}_{4}$ at $t=0.1 \mathrm{~s}$ over a ${ }^{16} \mathrm{O}_{2}$ preoxidized Pt gauze. (2) Transient response of argon. (3) The $\mathrm{CO}$ transient response from a pulse of CO over a prereduced $\mathrm{Pt}$ gauze. (4) The $\mathrm{C}^{16} \mathrm{O}$ transient response from alternating pulses of ${ }^{18} \mathrm{O}_{2}$ followed by $\mathrm{CH}_{4}$ at $t=0.1$ s over a ${ }^{16} \mathrm{O}_{2}$ preoxidized Pt gauze.

Its response is shown as curve 3 in Fig. 4. The shape of the response of a pulse of carbon monoxide (curve 3 ) is rather close to an inert argon pulse shape (curve 2) and does not show any tailing.

The same trend of results as described above was observed in the temperature interval between 800 and $1100^{\circ} \mathrm{C}$.

\section{DISCUSSION}

On the basis of the current data the following reaction scheme is proposed:

TABLE 2

\section{Product Distribution from a Pulse of ${ }^{18} \mathrm{O}_{2}$ Followed by a Pulse of Methane over a Preoxidized $\left({ }^{16} \mathrm{O}\right)$ Pt Gauze at $900{ }^{\circ} \mathrm{C}$}

\begin{tabular}{ccccc}
$\begin{array}{c}\text { Time interval } \\
\text { between }{ }^{18} \mathrm{O}_{2} \\
\text { and } \mathrm{CH}_{4}(\mathrm{~s})\end{array}$ & $X_{\mathrm{CH} 4}$ & $S_{\mathrm{C} 180}$ & $S_{\mathrm{C} 160}$ & $\Sigma S_{\mathrm{CO}}$ \\
\hline 0.1 & 0.35 & 0.14 & 0.02 & 0.16 \\
0.5 & 0.31 & 0.26 & 0.18 & 0.44 \\
1.0 & 0.26 & 0.39 & 0.49 & 0.88 \\
2.0 & 0.24 & 0.34 & 0.62 & 0.96 \\
3.0 & 0.24 & 0.31 & 0.65 & 0.96 \\
\hline
\end{tabular}

$$
\begin{aligned}
\mathrm{O}_{2}(\mathrm{~g}) & \mapsto \mathrm{O}_{\mathrm{s}} \\
\mathrm{O}_{\mathrm{s}} & \rightarrow \mathrm{O}_{\mathrm{b}} \\
\mathrm{O}_{\mathrm{b}} & \rightarrow \mathrm{O}_{\mathrm{s}} \\
\mathrm{CH}_{4}(\mathrm{~g}) & \rightarrow \mathrm{CH}_{x, \mathrm{ads}}+(4-x) \mathrm{H}_{\mathrm{ads}} \\
& \rightarrow \mathrm{C}_{\mathrm{ads}}+4 \mathrm{H}_{\mathrm{ads}} \\
2 \mathrm{H}_{\mathrm{ads}} & \mapsto \mathrm{H}_{2}(\mathrm{~g}) \\
2 \mathrm{H}_{\mathrm{ads}}+\mathrm{O}_{\mathrm{s}} & \mapsto \mathrm{H}_{2} \mathrm{O}(\mathrm{g}) \\
\mathrm{C}_{\mathrm{ads}}+\mathrm{O}_{\mathrm{s}} & \rightarrow \mathrm{CO}_{\mathrm{ads}} \\
\mathrm{CO}_{\mathrm{ads}} & \mapsto \mathrm{CO}_{(\mathrm{g})} \\
\mathrm{CO}_{\mathrm{ads}}+\mathrm{O}_{\mathrm{s}} & \rightarrow \mathrm{CO}_{2}(\mathrm{~g}) .
\end{aligned}
$$

The oxygen uptake during the preoxidation of the catalyst was much larger than an adsorbed monolayer for both oxidation procedures (Table 1). This means that, in addition to a dissociative adsorption of oxygen on the platinum surface step [1], there is an uptake of oxygen by bulk platinum as described by step [2]. Oxygen uptake in the same order of magnitude has previously been reported during oxygen pulsing over a platinum sponge in the TAP reactor (4). In a series of simultaneous pulses of oxygen and methane over a reduced platinum gauze (Fig. 1), oxygen is initially adsorbed at the platinum surface, followed by diffusion into the bulk rather than reacting with surface carbon. This suggests that surface oxygen is rapidly converted into bulk oxygen through step [2a] to oxidize more than the surface platinum layer. Then a stabilized oxidized state is reached defining the working platinum catalyst under the conditions applied in this study.

The observed oxygen scrambling into ${ }^{16} \mathrm{O}^{18} \mathrm{O}$ on pulsing ${ }^{18} \mathrm{O}_{2}$ over a gauze saturated in bulk ${ }^{16} \mathrm{O}$ supports that ${ }^{18} \mathrm{O}_{2}$ chemisorbs reversibly and dissociatively on platinum (reaction [1]) and that there is an exchange between the bulk and the surface (steps [2a] and [2b]).

The lack of tailing on the methane pulse indicates an irreversible methane adsorption (step [3]). The extent of the dissociation can not be directly deduced from these data. However, the marked tailing on the hydrogen signal as shown in Fig. 2 suggests that the partly dehydrogenated carbon species $\left(\mathrm{CH}_{3}, \mathrm{CH}_{2}\right.$, or $\left.\mathrm{CH}\right)$ has a significant surface lifetime. On subsequent oxygen pulses small amounts of carbon monoxide and carbon dioxide were observed, but no significant amounts of water, indicating that step [3] is completed within a few seconds.

The adsorbed hydrogen atoms can either combine through step [4] into hydrogen gas or can react with surface oxygen to form water (step [5]). The pulse response of hydrogen over oxidized platinum indicated that its dissociative adsorption is fast and reversible. A similar analysis showed a reversible adsorption of water.

Comparison of the responses of $\mathrm{C}^{18} \mathrm{O}$ and $\mathrm{C}^{16} \mathrm{O}$ (Fig. 4, curves 1 and 4 ) clearly shows the rapid formation of the 
former, while the production of the latter continues for several seconds. Therefore the reaction between surface carbon and ${ }^{18} \mathrm{O}$, mainly located on the surface as it was produced from a recent pulse of gaseous ${ }^{18} \mathrm{O}_{2}$, is relatively fast, whereas the reaction of surface carbon and ${ }^{16} \mathrm{O}$, mainly originating from the bulk, is considerably slower but can continue for a long time due to the large quantities of bulk ${ }^{16} \mathrm{O}$ available. Surface oxygen is rapidly depleted once the gas phase oxygen concentration goes to zero due to its desorption under vacuum conditions. The difference in rate between the formation of $\mathrm{C}^{18} \mathrm{O}$ and $\mathrm{C}^{16} \mathrm{O}$ suggests a diffusion of ${ }^{16} \mathrm{O}$ from the bulk to the surface (step [2b]), typically a slow process. An estimate for the time of oxygen diffusion is given by the difference between the average residence times of $\mathrm{C}^{16} \mathrm{O}$ and $\mathrm{C}^{18} \mathrm{O}$ and amounts to $0.3 \mathrm{~s}$ at $900^{\circ} \mathrm{C}$. An order of magnitude diffusion coefficient of $10^{-19} \mathrm{~m}^{2} \mathrm{~s}^{-1}$ can be calculated if a diffusion distance of one platinum monolayer is assumed. This stems from the idea that ${ }^{16} \mathrm{O}$, which is most likely to react, is located just underneath the surface. The incorporation of oxygen into the platinum bulk is an activated process since at relatively low temperatures the amount of oxygen uptake corresponds well with the number of surface platinum atoms.

The ratio $\mathrm{C}^{18} \mathrm{O} / \mathrm{C}^{16} \mathrm{O}$ decreases with increasing pulse interval (Table 2). The residence time of surface oxygen is short due to the fast desorption rate at high temperatures under vacuum conditions. Increasing the pulse interval decreases the concentration of surface oxygen at the time of the injection of methane. Bulk oxygen is much more stable at these conditions, indicated by the negligible oxygen uptake that was observed after keeping an oxidized gauze under vacuum. So, by increasing the pulse interval, the diffusion of bulk oxygen and the recombination/desorption of ${ }^{18} \mathrm{O}$ are increasing, resulting in an increase in the surface concentration of ${ }^{16} \mathrm{O}$ at the expenses of ${ }^{18} \mathrm{O}$.

The reactivity of bulk oxygen toward carbon monoxide and hydrogen is very low. This can be concluded from pulsing $\mathrm{CO}$ or $\mathrm{H}_{2}$ over oxidized platinum without gas phase oxygen present. This resulted in very low conversions of approximately $2-5 \%$, while $30 \%$ conversion was obtained for methane under identical conditions. In contrast the reactivity of surface oxygen toward carbon monoxide and hydrogen is very high since at short pulse intervals between $\mathrm{O}_{2}$ and $\mathrm{CO}$ or $\mathrm{H}_{2}$, corresponding to high concentrations of surface oxygen, an almost complete conversion of carbon monoxide or hydrogen was observed. These conclusions are also supported by the labeled carbon dioxide product distribution. $\mathrm{C}^{18} \mathrm{O}_{2}$ is the first product, due to the fast reaction between surface carbon and surface ${ }^{18} \mathrm{O}$ followed by the fast reaction between adsorbed $\mathrm{C}^{18} \mathrm{O}$ and surface ${ }^{18} \mathrm{O}$. $\mathrm{C}^{18} \mathrm{O}^{16} \mathrm{O}$ follows a little later in time, due to the slower formation of $\mathrm{C}^{16} \mathrm{O}$. Very little $\mathrm{C}^{16} \mathrm{O}^{16} \mathrm{O}$ is formed because of the low probability of the reaction between ${ }^{16} \mathrm{O}$ originating from the bulk and $\mathrm{C}^{16} \mathrm{O}$.
A similar analysis for the formation of water was unfortunately impossible due to the overlap between the fragments of all (labeled) reactants and products and those of (labeled) water.

All this agrees well with the results of Lauterbach et al. (18), who investigated the properties of oxygen on $\operatorname{Pt}(111)$ surfaces by photoemission electron microscopy. They observed the diffusion of oxygen into the bulk platinum and referred to this species as subsurface oxygen. A negligible reactivity of subsurface oxygen with either carbon monoxide or hydrogen was observed. From their experiments as a function of temperature they estimated an activation energy of $63 \pm 21 \mathrm{~kJ} \mathrm{~mol}^{-1}$ for the incorporation of oxygen into the platinum bulk.

The pulse response of carbon dioxide was very close to the response of argon, indicating that its adsorption can be neglected and that the reverse reaction of step (8) can be ignored. This can be understood from the fact that under the applied conditions the contact time of carbon dioxide is too short and the oxygen surface concentration is too large for any significant reaction of carbon dioxide to occur.

The maxima of the carbon dioxide and water shown in Fig. 2 are observed prior to those of carbon monoxide and hydrogen. Moreover, the responses of carbon dioxide and water are quite narrow. In contrast to previous interpretations $(12,13)$ this does not imply that carbon monoxide and hydrogen arises from secondary reforming reactions involving carbon dioxide and water. Due to the high concentration of surface oxygen, initially all the methane is oxidized to carbon dioxide and water. When the surface oxygen is depleted and no more gas phase oxygen is present to replenish the surface, the remaining surface carbon is selectively converted into carbon monoxide by the reaction with oxygen that is diffusing from the bulk to the surface. Therefore carbon monoxide and hydrogen exit the reactor after carbon dioxide and water.

The above developed reaction mechanism explains well the change in selectivity as a function of pulse interval as reported in Fig. 3. As the concentration of surface oxygen decreases with increasing pulse interval the consecutive oxidation of carbon monoxide and hydrogen diminishes rapidly, resulting in very high selectivities. The product distribution is completely determined by the surface oxygen concentration. At high surface oxygen concentrations the consecutive reactions of carbon monoxide and hydrogen are much faster than their corresponding desorption steps. However, at low surface oxygen concentrations the diffusion of bulk oxygen is slow compared to the residence time of carbon monoxide and hydrogen and negligible complete oxidation occurs. The surface lifetime of carbon is much longer and the diffusion of oxygen becomes then rate determining for the formation of carbon monoxide. The desorption of oxygen originating from the bulk was found to be rather slow 
under TAP conditions which is due to the slow diffusion rate of bulk oxygen.

Figure 3 shows that the methane conversion is above $35 \%$ at high surface oxygen concentrations whereas it approaches $25 \%$ when the surface is depleted of oxygen. In line with the above discussion, that difference could arise from the fact that at low oxygen surface coverage, the methane conversion is limited by the oxygen diffusion from the bulk to the surface while at high oxygen surface coverage, another step, faster than bulk oxygen diffusion, would limit the overall process. Since the number of gas molecules is higher than the number of platinum surface atoms and adsorption can be considered as very fast compared to the surface reaction, the number of adsorption sites determines the methane conversion. Or in the form of an equation:

$$
X=\frac{N_{\text {sites }}}{N_{\mathrm{CH}_{4}}} .
$$

At low surface oxygen concentrations the catalytic cycle of the site (the time required for a site to convert a methane molecule) is low due to the slow diffusion of oxygen. By the time the site has become available for reaction, the methane gas concentration has become zero. On the contrary, at high surface oxygen concentrations the reoxidation of surface carbon is faster than the diffusion time of gas phase methane and the site is again available for methane adsorption, resulting in a higher methane conversion. Thus the ratio of the conversions at high and at low surface oxygen concentrations shows that at a conversion of 0.35 the same sites are working 1.4 times more than at a conversion of 0.25 .

The residence time of methane in the gas phase inside the catalyst zone for a thin catalyst layers can be calculated according to (20)

$$
\tau=\frac{\varepsilon \Delta L L_{2}}{D},
$$

where $\tau$ is the average residence time (s), $\varepsilon$ is the bed porosity $\left(\mathrm{m}_{\mathrm{g}}^{3} \mathrm{~m}_{\mathrm{r}}^{-3}\right), \Delta L$ the catalyst zone length $(\mathrm{m}), L_{2}$ the inert zone after the catalyst (m), and $D$ the Knudsen diffusion coefficient $\left(\mathrm{m}_{\mathrm{g}}^{3} \mathrm{~m}_{\mathrm{r}}^{-1} \mathrm{~s}^{-1}\right)$. For the current reactor configuration a residence time for methane of $0.5 \mathrm{~ms}$ was calculated. The apparent rate constant for the oxidation of surface carbon at high surface oxygen concentrations is thus $>2000 \mathrm{~s}^{-1}$.

As mentioned in the introduction, Mallens et al. (4) reported on the existence of three different kinds of oxygen species on a platinum sponge under vacuum conditions at $800^{\circ} \mathrm{C}$. They referred to these three species as platinum oxide, dissolved oxygen, and chemisorbed oxygen. According to their reaction network direct formation of carbon monoxide occurs via the oxygen present as platinum oxide and dissolved oxygen converts adsorbed carbon and hydrogen into carbon dioxide and water. The consecutive oxidation of carbon monoxide and hydrogen into carbon dioxide and water involves chemisorbed oxygen. The results presented in this study did not indicate the existence of dissolved oxygen. After an oxidation of the platinum gauze by a flow of oxygen, no further oxygen uptake was observed during a multipulse experiment, as was the case in the study by Mallens et al. The quantities of dissolved oxygen reported were rather low and the distinction between dissolved oxygen and platinum oxide is not very clear. The small amounts of additional oxygen uptake that was observed after exposure of an oxidized catalyst to vacuum conditions in this study is believed to correspond to a slow desorption of bulk oxygen and not to the formation of a different type of oxygen.

\section{CONCLUSION}

The partial oxidation of methane over platinum gauzes in the TAP reactor takes place through a direct path to carbon monoxide and hydrogen. At high temperatures oxidation of platinum proceeds beyond a surface layer, well into the bulk phase. The product distribution is determined by the surface oxygen concentration. In the presence of gas phase oxygen the surface oxygen concentration is very high and consecutive oxidation of carbon monoxide and hydrogen takes place. In the absence of gas phase oxygen, the diffusion of oxygen from the bulk toward the surface is slower than the desorption of carbon monoxide and hydrogen and syngas is produced with high selectivities. Therefore a strict control of the surface oxygen reactivity is a prerequisite for any highly selective direct oxidation process to syngas over platinum. This can be attained by reducing either its concentration or its mobility. The former requires a process that avoids the simultaneous presence of methane and oxygen in the gas phase. This could be accomplished by nonstationary reactor operation with an alternating feed of methane and oxygen. Preliminary experiments still in progress in the laboratory already demonstrated the validity of that concept which has also been investigated by other research groups over different metal catalysts $(21,11)$. The oxygen mobility can be modified by adding a different metal to the platinum. This is the case for platinum rhodium for which high syngas selectivities have been reported (22).

\section{ACKNOWLEDGMENTS}

The financial support from the Norwegian Research Council is greatly acknowledged.

\section{REFERENCES}

1. Rostrup-Nielsen, J. R., Catal. Today 18, 305 (1993).

2. Foulds, G. A., and Lapszewicz, J. A., Catalysis 11, 412 (1994).

3. Vermieren, W. J. M., Blomsma, E., and Jacobs, P. A., Catal. Today 13, 427 (1992).

4. Mallens, E. P. J., Hoebink, J. H. B. J., and Marin, G. B., Catal. Lett. 33, 291 (1995). 
5. Mallens, E. P. J., Hoebink, J. H. B. J., and Marin, G. B., J. Catal. 167, 43 (1997).

6. Hickman, D. A., Haupfear, E. A., and Schmidt, L. D., Catal. Lett. 17, 223 (1992).

7. Boucouvalas, Y., Zhang, Z., and Verykios, X., Catal. Lett. 40, 189 (1996).

8. Heitnes Hofstad, K., Sperle, T., Rokstad, O. A., and Holmen, A., Catal. Lett. 45, 97 (1997).

9. Heitnes Hofstad, K., Hoebink, J. H. H., Holmen, A., and Marin, G. B., Catal. Today 40, 157 (1998).

10. Fathi, M., Rokstad, O. A., and Holmen, A., submitted for publication.

11. Otsuka, K., Sunada, E., U shiyama, T., and Yamanaka, I., Stud. Surf. Sci. Catal. 107, 531 (1997).

12. Buyevskaya, O. V., Wolf, D., and Bearns, M., Catal. Lett. 29, 249 (1994).

13. Buyevskaya, O. V., Walter, K., Wolf, D., and Bearns, M., Catal. Lett. 38, 81 (1996).
14. Soick, M., Buyevskaya, O. V., Hohenberger, M., and Wolf, D., Catal. Today 32, 163 (1996).

15. Wang, D., Dewaele, O., De Groote, A. M., and Froment, G. F., J. Catal. 159, 418 (1996).

16. Gleaves, J. T., Yablonskii, G. S., Phanawadee, P., and Schuurman, Y., A ppl. Catal. A 160, 55 (1997).

17. Bergene, E., Tronstad, O., and Holmen, A., J. Catal. 146, 141 (1994).

18. Lauterbach, J., A sakura, K., and Rotemund, H. H., Surf. Sci. 313, 52 (1994).

19. Shekhtman, S. O., Yablonskii, G. S., Gleaves, J. T., and Chen, S., Chem. Eng. Sci. 54, 4371 (1999).

20. Poirier, M. G., and Sapundzhie, C., Int. J. Hydrogen Energy 22, 429 (1997).

21. Fathi, M., Heitness Hofstad, K., Sperle, T., Rokstad, O. A., and Holmen, A., Catal. Today 42, 205 (1998). 